\title{
Tibial plateau fractures: a lot more to come!
}

\author{
Michael J. Raschke ${ }^{1} \cdot$ Elmar Herbst $^{1}$
}

๑) Springer-Verlag GmbH Germany, part of Springer Nature 2020

In the last decade, therapeutic concepts in tibial plateau fractures have changed dramatically. This refers to the range of indications for operative treatment, pre- and postoperative evaluation, assessment and visualization, operative approach(es) as well as choice of implants.

This is a result of an increasing scientific and clinical interest amongst trauma surgeons [2, 7]. When searching for tibial plateau fractures on PubMed, it becomes evident that the number of research items is continuously growing. Nevertheless, there are still some open questions that need to be addressed in the near future. Thus, the current issue of the European Journal of Trauma and Emergency Surgery focusses fully on this specific topic.

About one third of tibial plateau fractures include a bicondylar, comminuted fracture pattern [5]. Surgical exposure, visualization and consequently reduction in such complex fractures is still challenging [9]. However, for the long-term results, an anatomic reduction is necessary to avoid accelerated progression of posttraumatic osteoarthritis [4, 14]. In contrast to this assumption, it is still not clear, how much of an intra-articular step-off can be tolerated in tibial plateau fractures [8]. Conflicting results due to a large heterogeneity in current literature make it difficult to draw any conclusions. In the current issue, the authors, therefore, focused on improving surgical exposure by optimizing the approaches to the tibial plateau.

Fracture mal-reduction is often seen for posterolateral pathologies. In the article "The concept of direct approach to lateral tibial plateau fractures and stepwise extension as needed", the authors describe an optimized stepwise extension of the conventional lateral approach to the tibial plateau and are providing a recipe for surgeons to avoid failure due to poor visualization [6]. Every trauma surgeon interested in tibial plateau fractures should be aware of these extended

Michael J. Raschke

michael.raschke@ukmuenster.de

1 Department of Trauma, Hand and Reconstructive Surgery, Westphalian Wilhelms University Muenster, Albert-Schweitzer-Campus 1, 48149 Muenster, Germany approaches described in detail in the current issue by Frosch et al. and Korthaus et al. [6, 10, 13].

Despite these conventional approaches, parts of the tibial plateau might not be properly seen intraoperatively. In such cases, fracturoscopy, arthroscopy and three-dimensional imaging might be helpful tools and should be available in every trauma center to obtain optimal postoperative results [3].

In a retrospective, multicenter cohort study from the Fracture Committee of the German Knee Society, 122 tibial plateau fractures have been followed clinically and radiographically for almost 3 years. In the current issue, it has been reported that in more than $95 \%$ clinical as well as radiological outcomes were good or even excellent [11]. Interestingly, Krause et al. found that impaired bone metabolism is an important risk factor for poor outcomes [11]. This entity is of high importance as a large percentile of our fractures will be accounted to an elderly population.

The report of such promising results should not allow us to lean back and fail to further improve as other articles found far inferior results [12]. This is represented by the fact, that malunions or loss of reduction are still a problem we are facing regularly. In these cases, osteotomy might be a good but technically demanding treatment option. In the article "Intraarticular osteotomy of malunited tibial plateau fractures: an analysis of clinical results with a mean follow-up after 4 years ", the authors reported on good outcomes with proper realignment of the lower limb axis as well as intra-articular step-offs 4 years after an osteotomy due to malreduction or non-union [1]. Nevertheless, these procedures should be limited to experts and centers with a high case load.

This issue thoroughly presents articles around the tibial plateau [1, 6, 10, 11, 15-17]. One important aspect needs, however, further investigations in the future: many surgeons are still focusing mainly on the osseous reconstruction, while soft tissues might be underestimated or even neglected. As preoperative magnetic resonance imaging might not always be available or might simply be too time consuming, intraoperative examination with subsequent dynamic fluoroscopy 
after fracture reduction and fixation could be a simple but efficient tool to rule out any relevant ligamentous instabilities [9].

This issue of the Journal of Trauma and Emergency Surgery sheds some light on the tibial plateau, but it shows at the same time that some open questions require further investigations, especially with regard to postoperative osteoarthritis and long-term results, proper fixation of small (central) fragments, bone augmentation as well as management of soft tissue injuries. At the same time, it means that we can expect further burning articles on tibia plateau fractures in the near future!

\section{Compliance with ethical standards}

Conflict of interest The authors have no competing interest.

\section{References}

1. Alm L, Frings J, Krause M, Frosch KH. Intraarticular osteotomy of malunited tibial plateau fractures: an analysis of clinical results with a mean follow-up after 4 years. Eur J Trauma Emerg Surg. 2020. https://doi.org/10.1007/s00068-020-01440-y.

2. Domnick C, Garcia P, Raschke MJ, Glasbrenner J, Lodde G, Fink $\mathrm{C}$, et al. Trends and incidences of ligament-surgeries and osteotomies of the knee: an analysis of German inpatient records 2005-2013. Arch Orthop Trauma Surg. 2017;137:989-95.

3. Domnick C, Kittl C, Herbst E, Kösters C, Herbort M, Glasbrenner $\mathrm{J}$, et al. Arthroskopisch assistierte Versorgung von Tibiaplateaufrakturen. Knie J. 2020;2:107-13.

4. Elsoe R, Johansen MB, Larsen P. Tibial plateau fractures are associated with a long-lasting increased risk of total knee arthroplasty a matched cohort study of 7,950 tibial plateau fractures. Osteoarthritis Cartilage. 2019;27:805-9.

5. Elsoe R, Larsen P, Nielsen NP, Swenne J, Rasmussen S, Ostgaard SE. Population-based epidemiology of tibial plateau fractures. Orthopedics. 2015;38:e780-786.

6. Frosch KH, Korthaus A, Thiesen D, Frings J, Krause M. The concept of direct approach to lateral tibial plateau fractures and stepwise extension as needed. Eur J Trauma Emerg Surg. 2020. https://doi.org/10.1007/s00068-020-01422-0.

7. Garcia P, Domnick C, Lodde G, Raschke MJ. Operative treatment in orthopedics and trauma surgery: are more operations carried out in Germany? Unfallchirurg. 2018;121:20-9.

8. Giannoudis PV, Tzioupis C, Papathanassopoulos A, Obakponovwe O, Roberts C. Articular step-off and risk of post-traumatic osteoarthritis. Evid Today Injury. 2010;41:986-95.

9. Herbst E, Briese T, Kittl C, Glasbrenner J, Schliemann B, Raschke MJ. Planung der Zugänge bei Tibiaplateaufraktur-Welche sollte man kennen? Knie J. 2020;2:82-9.

10. Korthaus A, Ballhause TM, Kolb JP, Krause M, Frosch KH, Hartel MJ. Extended approach to the lateral tibial plateau with central meniscal subluxation in fracture repair: feasibility and first clinical and radiographic results. Eur J Trauma Emerg Surg. 2020. https:// doi.org/10.1007/s00068-020-01467-1.

11. Krause M, Alm L, Berninger M, Domnick C, Fehske K, Frosch $\mathrm{KH}$, et al. Bone metabolism is a key factor for clinical outcome of tibial plateau fractures. Eur J Trauma Emerg Surg. 2020. https ://doi.org/10.1007/s00068-020-01537-4.

12. Manidakis N, Dosani A, Dimitriou R, Stengel D, Matthews S, Giannoudis P. Tibial plateau fractures: functional outcome and incidence of osteoarthritis in 125 cases. Int Orthop. 2010;34:565-70.

13. Raschke MJ, Kittl C, Domnick C. Partial proximal tibia fractures. EFORT Open Rev. 2017;2:241-9.

14. Snoeker B, Turkiewicz A, Magnusson K, Frobell R, Yu D, Peat $\mathrm{G}$, et al. Risk of knee osteoarthritis after different types of knee injuries in young adults: a population-based cohort study. Br J Sports Med. 2019. https://doi.org/10.1136/bjsports-2019-100959.

15. Menzdorf L, Drenck T, Akoto R, Hartel M, Krause M, Guttowski $\mathrm{M}$, et al. Clinical results after surgical treatment of posterolateral tibial plateau fractures ("apple bite fracture") in combination with ACL injuries. Eur J Trauma Emerg. 2020. https://doi.org/10.1007/ s00068-020-01509-8.

16. Henkelmann R, Krause M, Alm L, Glaab R, Mende M, Ull C, et al. Effect of fracturoscopy on the incidence of surgical site infections post tibial plateau fracture surgery. Eur J Trauma Emerg Surg. 2020. https://doi.org/10.1007/s00068-020-01486-y.

17. Dehoust J, Münch M, Seide K, Barth T, Frosch K.-H. Biomechanical aspects of the posteromedial split in bicondylar tibial plateau fractures - a finite-element investigation. Eur J Trauma Emerg Surg. 2020. https://doi.org/10.1007/s00068-020-01538-3. 